\title{
The Effect of Shoulder Coupling on the Residual Stress and Hardness Distribution in AA7050 Friction Stir Butt Welds
}

DOI:

10.1016/j.msea.2017.12.018

\section{Document Version}

Accepted author manuscript

Link to publication record in Manchester Research Explorer

Citation for published version (APA):

Sun, T., Reynolds, A. P., Roy, M. P., Withers, P., \& Prangnell, P. (2018). The Effect of Shoulder Coupling on the Residual Stress and Hardness Distribution in AA7050 Friction Stir Butt Welds. Journal of Materials Science and Engineering. A, 735. https://doi.org/10.1016/j.msea.2017.12.018

Published in:

Journal of Materials Science and Engineering. A

\section{Citing this paper}

Please note that where the full-text provided on Manchester Research Explorer is the Author Accepted Manuscript or Proof version this may differ from the final Published version. If citing, it is advised that you check and use the publisher's definitive version.

\section{General rights}

Copyright and moral rights for the publications made accessible in the Research Explorer are retained by the authors and/or other copyright owners and it is a condition of accessing publications that users recognise and abide by the legal requirements associated with these rights.

\section{Takedown policy}

If you believe that this document breaches copyright please refer to the University of Manchester's Takedown Procedures [http://man.ac.uk/04Y6Bo] or contact uml.scholarlycommunications@manchester.ac.uk providing relevant details, so we can investigate your claim.

\section{OPEN ACCESS}




\title{
The Effect of Shoulder Coupling on the Residual Stress and Hardness Distribution in AA7050 Friction Stir Butt Welds
}

\author{
T. Sun ${ }^{1}$, A. P. Reynolds ${ }^{2}$, M.J. Roy ${ }^{3}$, P.J. Withers ${ }^{1}$, P.B. Prangnell ${ }^{1}$ \\ ${ }^{1}$ School of Materials, the University of Manchester, Manchester M13 9PL, UK \\ ${ }^{2}$ Department of Mechanical Engineering, University of South Carolina, 300 Main Street, Columbia, \\ SC 29 208, USA \\ ${ }^{3}$ School of Mechanical, Aerospace and Civil Engineering, the University of Manchester, \\ Manchester M13 9PL, UK
}

\begin{abstract}
The effect of shoulder coupling in friction stir welding (FSW) on the distribution of residual stresses, microstructure and hardness has been investigated by comparing welds manufactured with a conventional tool, using different levels of downforce, to joints produced using a stationary shoulder (SSFSW). The welds were produced in AA7050-T7651 $6.35 \mathrm{~mm}$ plate with the same travel speed and similar power levels. Reducing the tool downforce in FSW led to a decrease in the overall shoulder input power, but a minimal reduction in the weld zone hardness and peak residual stresses. In contrast, relative to FSWs made with a similar input power, the stationary shoulder led to much more significant microstructure and property changes including; a reduction in the HAZ width and increase in the minimum weld zone hardness level and a significant reduction in the peak tensile residual stresses (by $\sim 25 \%$ ). With SSFSW, the improvement found in the hardness and residual stress distribution from eliminating the energy dissipated by the tool shoulder, could be directly correlated to a reduction in the weld temperature and narrowing of the thermal field, which reduced the size of the HAZ and region of plastic misfit responsible for the weld residual stresses. By comparing the results with previous work it was found that, apart from using a stationary shoulder, the most important welding parameter affecting the weld zone size peak tensile stresses was the travel speed, with longitudinal residual stresses doubling on increasing the travel speed from 100 to $400 \mathrm{~mm} / \mathrm{min}$.
\end{abstract}

Keywords: contour method, aluminum alloys, friction stir welding, stationary shoulder, downforce 


\section{Introduction}

Friction stir welding (FSW) has revolutionized the joining of high strength aluminum alloys by avoiding their inherent propensity to generate defects, such as porosity and solidification cracks, in fusion welding processes [1, 2]. In FSW, the tool downforce is an important machine-controlled parameter, in addition to the more commonly investigated travel speed and rotation rate [3, 4]. For example, Upadhyay et al. [5] have demonstrated that downforce plays a significant role in weld quality, as an insufficient downforce can result in volumetric defects, while an excessive downforce can lead to an overheated surface and excessive flash, as well as thinning of the weld zone. In the standard process, the downforce helps to avoid cavitation and strongly influences the contact area of the shoulder and the extent of sticking/slipping at the tool-workpiece interface. This can markedly change the relative power dissipated by the pin and shoulder [5-7]. To date, despite its important role, the effect of downforce on heat generation and weld performance has not been widely reported. For example, Altenkirch et al. [8] only studied the effect of downforce when applying FSW to a 5 mm thick Al-Li AA2199 alloy plate in a very limited range. Whereas, Elangovan et al. [9] have reported that downforce has an obvious effect on the distribution of strengthening precipitates and grain size within the weld nugget. In comparison no information is currently available on the effect of downforce on the residual stresses in FSWs and little on the welds hardness profiles and related microstructural changes which controls their yielding behavior in transverse loading. This is despite the level of tool shoulder-workpiece coupling being a significant aspect of the process that can strongly influence the overall heat generated and its distribution [6]. In addition, there is also potential for a mechanical effect from compression of the weld and the torque induced by the shoulder into the workpiece surface [10].

Stationary shoulder friction stir welding (SSFSW) is a newly developed variant of the conventional FSW process [11] and represents an extreme FSW condition; i.e. because the shoulder does not rotate, minimal heat is generated at the weld crown and a stationary shoulder does not as significantly compress the weld, or impart any torque into the workpiece. Recent studies have demonstrated that SSFSW can have significant advantages for joining high strength aluminum alloys, including a more uniform through thickness microstructure, and heat affected zone (HAZ), superior mechanical properties and an improved surface finish [12, 13]. However, at present, its influence on residual stresses is less understood [14].

In previous studies, we have directly compared the microstructure, properties, and residual stresses found in welds produced by the FSW and SSFSW processes [12, 14], using identical geometries for the tool shoulder and pin. However, with the pin design previously employed different rotation rates were required, because the lower heat input with the SSFSW process resulted in no overlap of the 
respective process windows. The two processes were therefore compared by evaluating their torque-rotation rate decay curves and finding the region of minimum power for each process. In this work, although a higher rotation rate was used for SSFSW compared to the FSW process, better cross-weld tensile properties and less HAZ damage was still found for the SSFSW process. The SSFSW also showed an ' $M$ ' shape longitudinal residual stress distribution, consistent with the typical profile seen in conventional FSWs in high strength aluminum alloys $[15,16]$, but it had a narrower and lower tensile residual stress field when compared to the FSWs.

As discussed by Colegrove and Shercliff [17], in FSW it is possible to increase the pin heat input by employing a larger diameter probe and therefore the minimum rotation rate required for SSFSW will be reduced, providing the potential for comparing both process with identical welding parameters. Furthermore, as discussed by Upadhyay [5], the shoulder heat input in FSW can also be significantly reduced when a lower tool downforce is employed, which could narrow the differences between SSFSW and FSW, in terms of their respective heat inputs, mechanical behavior, and residual stress distributions.

In our current work, we have therefore extended our investigation into the effect of shoulder coupling on the weld zone microstructure, hardness and relative residual stress behavior seen in FSW and SSFSW, by directly comparing the behavior of FSWs with reduced levels of downforce, to SSFSW conducted at the same rotation rate. In addition, we have summarized the available data for welds made with different rotation rates and travel speeds, in order to identify the welding parameters that most strongly affect the weld heat affected zone and peak residual stresses.

\section{Experimental Procedures}

The material used in this study was $6.35 \mathrm{~mm}$ thick, hot rolled AA7050-T7651 plate, having a nominal composition of $5.6 \% \mathrm{Zn}, 2.5 \% \mathrm{Mg}, 1.6 \% \mathrm{Cu}$ and $0.23 \% \mathrm{Cr}$. The welds were produced in a butt weld configuration at the University of South Carolina. To increase the strength of the pin and allow a lower rotation rate for SSFSW comparable with that of FSW, the pin used had a larger diameter than employed previously [14]. Both tools had a H13 steel shoulder with a diameter of $17.8 \mathrm{~mm}$ and a MP-159 $6.1 \mathrm{~mm}$ long treated tri-flat conical pin, with a root diameter of $7.9 \mathrm{~mm}$, as opposed to the $6.1 \mathrm{~mm}$ diameter pin employed previously $[12,14]$. Thermocouples were inserted into the tool pins at mid-height and in the shoulder of the FSW tool to record the thermal history [5, 18]. The matrix of welding conditions investigated is summarized in Table 1. Welding was carried out under downforce control at $640 \mathrm{rpm}$ and $400 \mathrm{~mm} / \mathrm{min}$. Conventional FSWs were produced using systematically varied levels of downforce across the maximum range where defect-free welds could be produced, within acceptable limits of undercut, which for this material was found to be 
$24.5 \mathrm{kN}$ to $33.4 \mathrm{kN}$. Furthermore, additional stationary shoulder welds were produced with a higher rotation rate to compare the relative importance of different welding parameters on the welds microstructures and residual stress distributions.

\begin{tabular}{cccccc}
\hline Welding Technique & $\begin{array}{c}\text { Rotation speed } \\
(\mathrm{rpm})\end{array}$ & $\begin{array}{c}\text { Travel speed } \\
(\mathrm{mm} / \mathrm{min})\end{array}$ & $\begin{array}{c}\text { Downforce } \\
(\mathrm{kN})\end{array}$ & $\begin{array}{c}\text { Pressure } \\
(\mathrm{MPa})\end{array}$ & $\begin{array}{c}\text { Power } \\
(\mathrm{kW})\end{array}$ \\
\hline SSFSW & 1000 & 400 & 42 & 144 & 3.7 \\
SSFSW & 640 & 400 & 44 & 150 & 2.9 \\
FSW & 640 & 400 & 24.5 & 125 & 2.9 \\
FSW & 640 & 400 & 28.9 & 145 & 3.3 \\
FSW & 640 & 400 & 31.2 & 155 & 3.6 \\
FSW & 640 & 400 & 33.4 & 170 & 3.4 \\
\hline
\end{tabular}

Table 1 The matrix of welding parameters employed in this paper.

To obtain optical macro views of the weld cross sections, standard metallographic procedures were used. For EBSD-SEM orientation mapping samples were lightly electropolished in $20 \%$ perchloric acid in ethanol $\left(-15^{\circ} \mathrm{C}, 20 \mathrm{~V}\right)$ to produce a strain free surface. EBSD maps were used to characterize the grain structure and grain size in the center of the weld nuggets through the plate thickness to check the relative weld temperatures by inference from the nugget grain sizes [19-21]. Automated micro-hardness maps were performed using a Struers DuraScan 80 automated Vickers hardness tester with an applied load of $0.5 \mathrm{~kg}$ for 10 seconds on transverse-normal (TD-ND) cross sections of all the welds after natural ageing for five months. Each hardness map contained $\sim 1800$ data points with $0.5 \mathrm{~mm}$ spacing between indents. High resolution SEM with a Zeiss Sigma VP field emission gun-scanning electron microscope (FEG-SEM) was used to the welds coarse scale precipitation behavior.

The contour method was employed to measure the longitudinal (WD) residual stress distributions in the welds, as a function of the processing parameters. The contour method is a destructive technique developed by Prime [22] that can provide a 2-D stress map over a given weld cross section [23-25]. Measurements were carried out by cutting the welds perpendicular to the welding direction (WD) using wire electro-discharge machining (EDM) with a $250 \mu \mathrm{m}$ diameter brass wire in a low power 'skim-cutting' mode. In this procedure, consideration of the fixture design and cutting strategy are important to reduce the possibility of plastic deformation and non-consistent material removal. The relaxed EDM cut surfaces were then scanned using a Nanofocus $\mu$ Scan laser profilometer and a 
bivariate cubic spline fit was applied to the average of the two surface displacements, to define the surface boundary in the subsequent finite element elastic analysis using ABAQUS ${ }^{\mathrm{TM}}$. Full details of the methodology used can be found in our previous study [14].

\section{Results and discussion}

\section{Effect of shoulder contact conditions on energy dissipation}

In Fig. 1(a), the welding power calculated from the torque measured by the FSW machine is plotted against downforce for the FSW welds, with the same travel speed and rotation rate $(400 \mathrm{~mm} / \mathrm{min}$ and $640 \mathrm{rpm}$, respectively). For comparison purposes, the average welding power determined for the welds produced using the SSFSW process are also plotted as a horizontal dashed line. With the FSW process it can be seen that the welding power initially increases with higher downforce, but then appears to reach a limit. The increase in power with increasing downforce results from an increase in the contact area between the tool and workpiece, and the related increase in shear resistance under sliding conditions (Coulomb friction) and the proportion of the tool surface where sticking occurs [26]. The fact that a limit is reached and the torque then starts to reduce with a higher down forces occurs because there is a maximum contact area and the material strength under the shoulder will reduce dramatically with temperature as the material approaches its melting point [5]. Overall, it can be seen from Fig. 1(a) that by reducing the downforce within the constraints of producing defect-free welds, it was possible to reduce the overall welding power by the relatively modest amount of approximately $20 \%$.

(a)

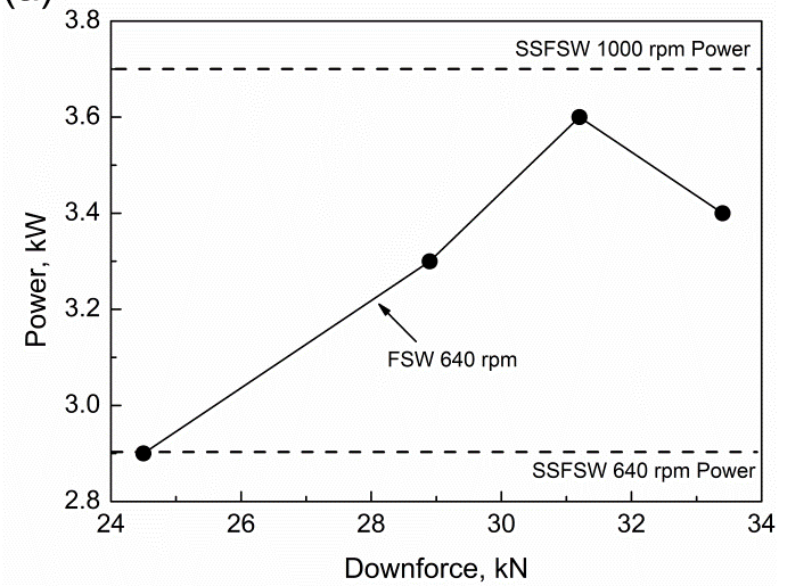

(b)

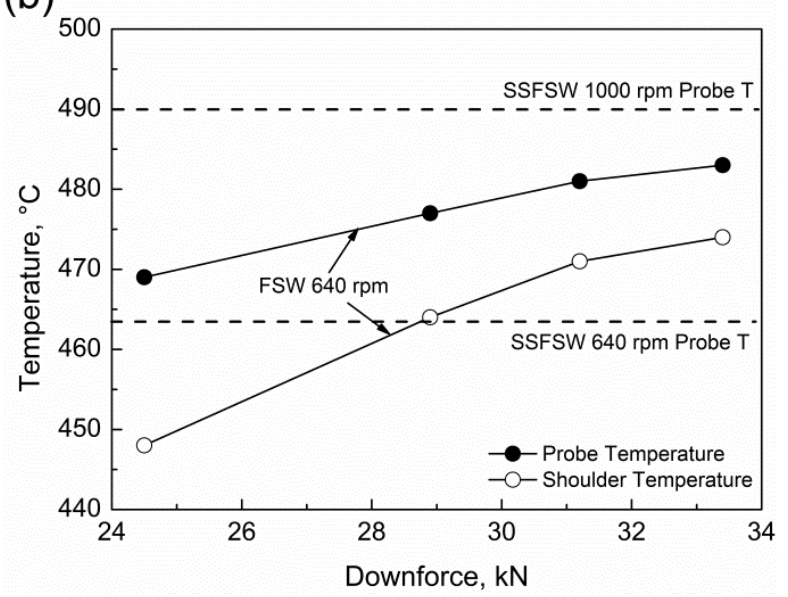

Fig. 1: (a) the welding power calculated from the machine torque and (b) the probe and shoulder temperatures recorded at steady state, for increasing downforce with the FSW process with a constant rotation rate $(640 \mathrm{rpm})$, compared to that for SSFSW. Data for SSFSW is shown as horizontal lines for the same travel speed $(400 \mathrm{~mm} / \mathrm{min})$. 
In comparison, the power dissipated in the workpiece with the stationary shoulder tool at the same rotation rate of $640 \mathrm{rpm}$ was substantially lower than that relative to FSW with a high down force, but by reducing the downforce for FSW to the lowest level that could be employed, a similar welding power was achieved for both processes (Fig. 1a). Therefore, in principle, for the lowest downforce FSW condition, the weld microstructures and residual stresses should be directly comparable with the $640 \mathrm{rpm}$ SSFSWs, as they had similar heat inputs. Finally, it can be seen that by using a higher rotation rate of $1000 \mathrm{rpm}$, the power dissipated by the SSFSW process was increased to greater than that found for the highest power obtained by FSW at $640 \mathrm{rpm}$, with a high downforce.

It has previously been shown in FSW that the temperature measured by a thermocouple embedded in the pin corresponds closely to that of the workpiece, when steady state conditions are attained, and can provide a representative measurement of the temperature within the weld nugget $[5,18]$. Fig. 1(b) provides average mid weld depth pin temperature measureme6nts from all the welds studied. The results give readings in the relatively narrow range of $20^{\circ} \mathrm{C}$, with a maximum of 483 ${ }^{\circ} \mathrm{C}$, where the upper limit is close to the incipient melting point of the 7050 alloy (488 ${ }^{\circ} \mathrm{C}$ [27]). It can be seen that for the FSW data the temperature fell to $469^{\circ} \mathrm{C}$, when the lowest viable downforce was employed. However, this was still not as low as that found for the SSFSW process with the same rotation rate $(640 \mathrm{rpm})$, which was recorded as $463{ }^{\circ} \mathrm{C}$. At first sight the results therefore suggest a slight disconnect between the difference in measured pin temperatures and the similar welding torques recorded for the SSFSW and lowest downforce FSW condition. That is to say, as the rotating shoulder would still be expected to generate a significant proportion of the heat [7], even with a low downforce, it seems unlikely that the nugget temperature should be slightly lower for the SSFSW process when the pin is generating all of the heat with the same power dissipation. However, as the difference in temperature is relatively small, it is possible that this anomaly is caused by a difference in the thermocouple placement height within the respective tools pins, which from previous experience of changing tools can cause a variation of $\pm 5^{\circ} \mathrm{C}$. In addition, the thermocouple makes a measurement at single height and in FSW identical powers can be dissipated with a different local distribution (for example through the workpiece thickness). This discrepancy will be discussed further below where the nugget grain sizes have been characterized as an independent check of the relative weld temperatures. Finally, when the SSFSW rotation rate was increased to $1000 \mathrm{rpm}$, the higher power led to a larger increase in the measured pin temperature to $490{ }^{\circ} \mathrm{C}$, which was higher than seen in the FSWs and above the material's incipient melting point. 
For the FSW process, the temperatures recorded in the tool shoulder are also shown in Fig. 1(b). It can be seen that overall the shoulder temperatures were about $10-20{ }^{\circ} \mathrm{C}$ lower than measured in the tool pin and, as would be expected, were more strongly affected by down force. This is due to the direct effect of downforce on the shoulder-workpiece contact area, which led to a decrease in the measured temperature by approximately $25^{\circ} \mathrm{C}$ when it was reduced from 33.4 to $24.5 \mathrm{kN}$.

\section{Weld zone microstructures and hardness distributions}

Examples of TD-ND full weld cross sections are shown in Fig. 2. Micro hardness maps and corresponding hardness line profiles at the mid-thickness are also provided in Fig. 3 and 4. It should be noted that all the hardness values were measured after post-weld natural ageing for five months. In Fig. 2, the typical weld zones can be readily identified (e.g. [14, 28, 29]) with the distinction that, in the case of the SSFSWs there is less expansion of the heat affected zone (HAZ) and severely deformed fine grained nugget region at the top surface under the shoulder contact area. Overall, Fig. 3 confirms that in the SSFSW process the weld zones and HAZs were less wide and more uniform through the plate thickness [12]. This benefit arises primarily because they are less spread out under the shoulder contact area due to the absence of the high local heat input and deformation generated by a rotating shoulder. In the FSWs, progressively reducing the shoulder downforce can also be seen to decrease the width of the HAZ at the weld crown, although this effect is relatively modest and even with the lowest downforce the weld hardness profiles (Fig. 3 and 4) are not as dramatically reduced in width as for the SSFSW process with the same rotation rate.

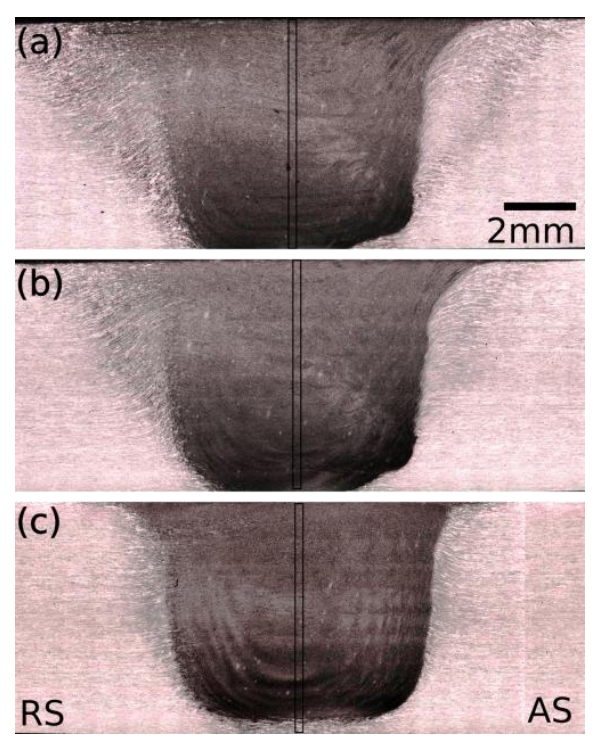

Fig. 2: Typical weld macro-cross sections showing: (a) and (b) FSWs produced with the maximum $(34.5 \mathrm{kN})$ and minimum $(24.3 \mathrm{kN})$ downforce, respectively, and (c) a SSFSW. All welds were produced with the same travel speed travel speed $(400 \mathrm{~mm} / \mathrm{min})$ and rotation rate $(640 \mathrm{rpm})$. The 
black rectangles highlight the region investigated by EBSD in Fig. 6. The advancing side (AS) is on the right.

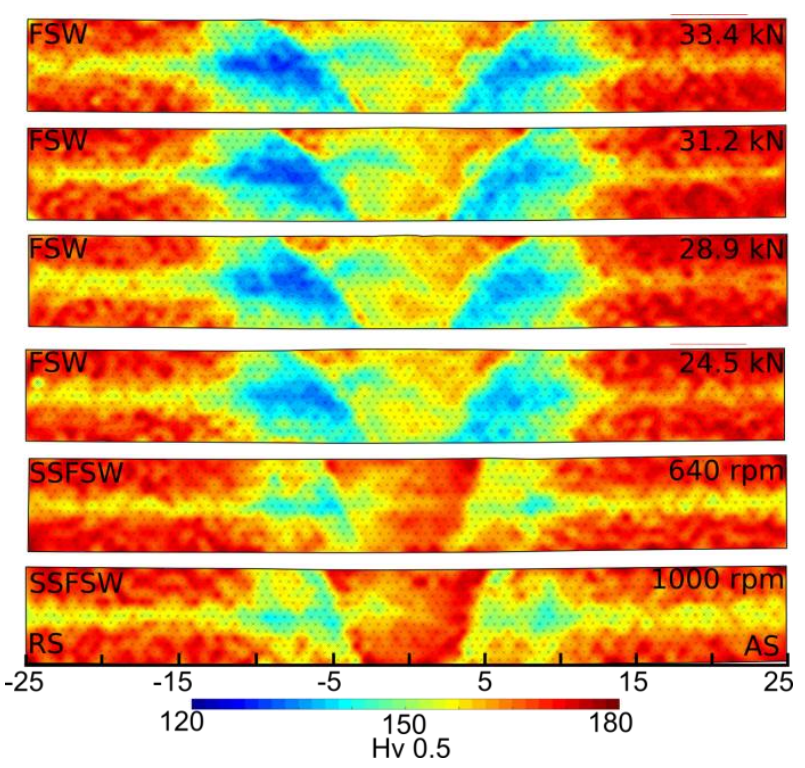

Fig. 3: Hardness maps from cross sections of the FSWs with reducing down force (33.4 to $24.5 \mathrm{kN}$ ) compared to SSFSWs, measured after natural ageing for 5 months; all produced with the same travel speed $(400 \mathrm{~mm} / \mathrm{min})$. The FSWs all had the same rotation rate of $640 \mathrm{rpm}$, whereas SSFSWs are shown for $640 \mathrm{rpm}$ and $1000 \mathrm{rpm}$. (AS = weld advancing side; RS = retreating side.)

(a)

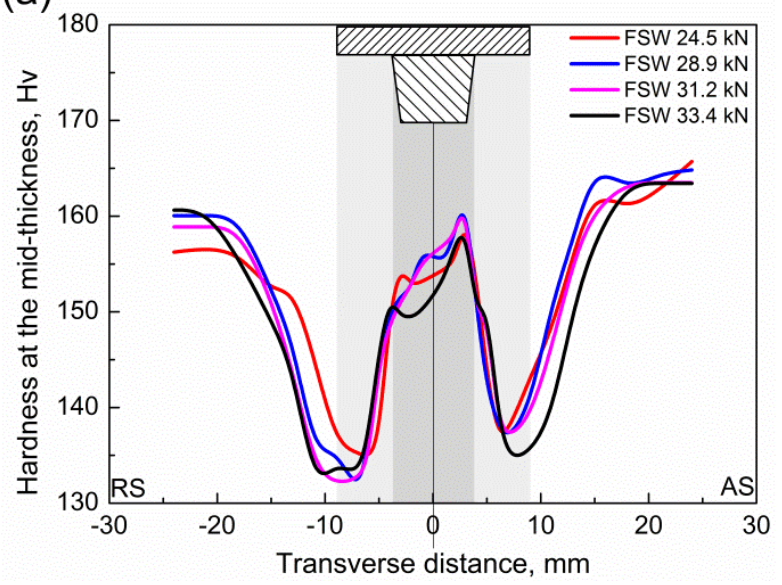

(b)

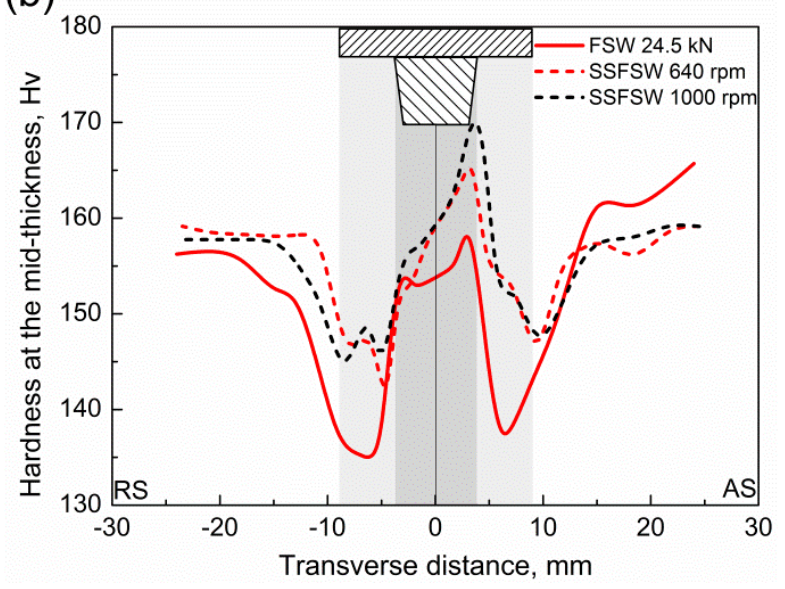

Fig. 4: Weld hardness profiles measured at mid-thickness for; (a) FSWs with reducing down force (33.4 to $24.5 \mathrm{kN}$ ) and (b) comparison between SSFSW with high (1000 rpm) and standard (640 rpm) rotation rates and FSW with the lowest downforce of $24.5 \mathrm{kN}$ (640 rpm) (measured after natural ageing for 5 months).

Consistent with previous research on FSW of 7xxx series aluminum alloys in a pre-aged condition (e.g. T7651) [12, 19, 28, 30], in Fig. 4, all the hardness profiles exhibit a 'W' shape distribution. 
Despite the overall welding power being reduced from 3.6 to $2.9 \mathrm{~kW}$, there is only a slight trend observed with reducing downforce. Specifically, only a small decrease in HAZ width and increase in the hardness minima is observed. This finding is in agreement with Reynolds et al. [31], who proposed that in precipitation hardening aluminum alloys like the 7xxx series, the hardness minimum in the HAZ is mainly influenced by the welding speed. By comparison, the hardness profile for the $640 \mathrm{rpm}$ SSFSW weld shows a much improved hardness minima and a significantly narrower HAZ (Fig. 4(b)). The higher heat input SSFSW specimen welded at $1000 \mathrm{rpm}$ also had a narrower HAZ than the conventional FSW, which is similar to that of the $640 \mathrm{rpm}$ SSFSW specimen. The effect of the change in shoulder coupling is summarized in Fig. 5 where the average hardness minima at mid thickness, is plotted against down force for FSWs and directly compared between the two processes. It should be noted that the hardness level at the minima position is of particular importance to the joints' mechanical performance because it determines the stress at which yielding first occurs in transverse loading [12].

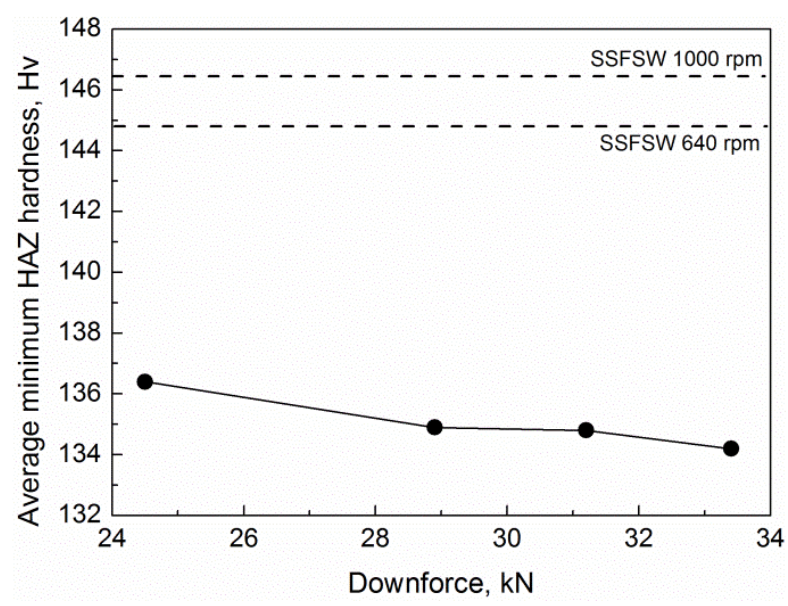

Fig. 5: Average hardness at the HAZ minim position measured at mid thickness, plotted against down force for the FSW process with a constant rotation rate $(640 \mathrm{rpm})$, compared to that for SSFSW with the same travel speed travel speed (400 $\mathrm{mm} / \mathrm{min})$ shown as horizontal lines.

Although there is a slight increase in the hardness minima (Fig. 5) and reduction in HAZ width (Fig 4), overall, these results show that reducing the down force in FSW (in the range where the process is still stable) has a minimal effect on the hardness level at the critical minima position. In contrast, there is a step-change improvement in both the hardness minima level and HAZ width, when using a stationary shoulder tool. This also implies that the characteristic thermal field in FSW is wider than that in SSFSW, even with a low downforce and when the input powers are nominally similar (Fig. 1(a)).

For all the welds, the hardness distribution in the weld nugget was found to be non-uniform, with a higher value on the advancing side (AS). Wade and Reynolds [32] have reported that this asymmetry can be attributed to a difference in strain level and strain rate within the weld nugget 
from the advancing to retreating sides. Specifically, since the local temperature is largely dependent on the rate of plastic deformation, there will be a slightly higher temperature on the advancing side of the weld, which could lead to small differences in the level of solutionisation and the extent of subsequent natural ageing. This difference is most obvious near the mid-thickness. However, at this position, the difference in hardness across the weld has been influenced by the lower centerline hardness seen in the parent plate, caused by macro segregation during DC casting and subsequent hot rolling. This suggests there may also have been more vertical material flow on the advancing side of the nugget of material originally at the plate center, as where the concentration of potential solute is lower this will reduce the local hardness that results from post-weld natural ageing. When considering these results it should also be noted that the peak in hardness in some instances rose slightly higher than the background parent plate level of 165-170 Hv. This can be partly attributed to the strong natural ageing behavior of this alloy, relative to the overaged T7651 temper, and the dramatic reduction in grain size in the nugget which can also make a minor contribution to the strength increase of the order of $5-10 \mathrm{H}_{\mathrm{V}}[19]$.

It is also interesting that a lower weld nugget hardness was determined in the FSWs when a relatively higher peak weld temperature was measured at the mid-thickness than in SSFSW. It is commonly assumed that a higher peak weld temperature will lead to a higher driving force for subsequent natural ageing, due to the greater level of solutionisation that occurs in the nugget and, hence, a higher post-weld hardness [19]. This behavior in particular occurs when the temperature rise in the nugget region increases to exceed the alloys solvus temperature. To verify the inconsistency seen between the measured relative weld temperatures and the recorded welding powers (described above) and explain why the hardness levels in the weld nuggets seemed at odds with the temperature measurements, the grain size distributions within the weld nuggets were characterized by EBSD down each weld center (Fig. 6 and 7). 

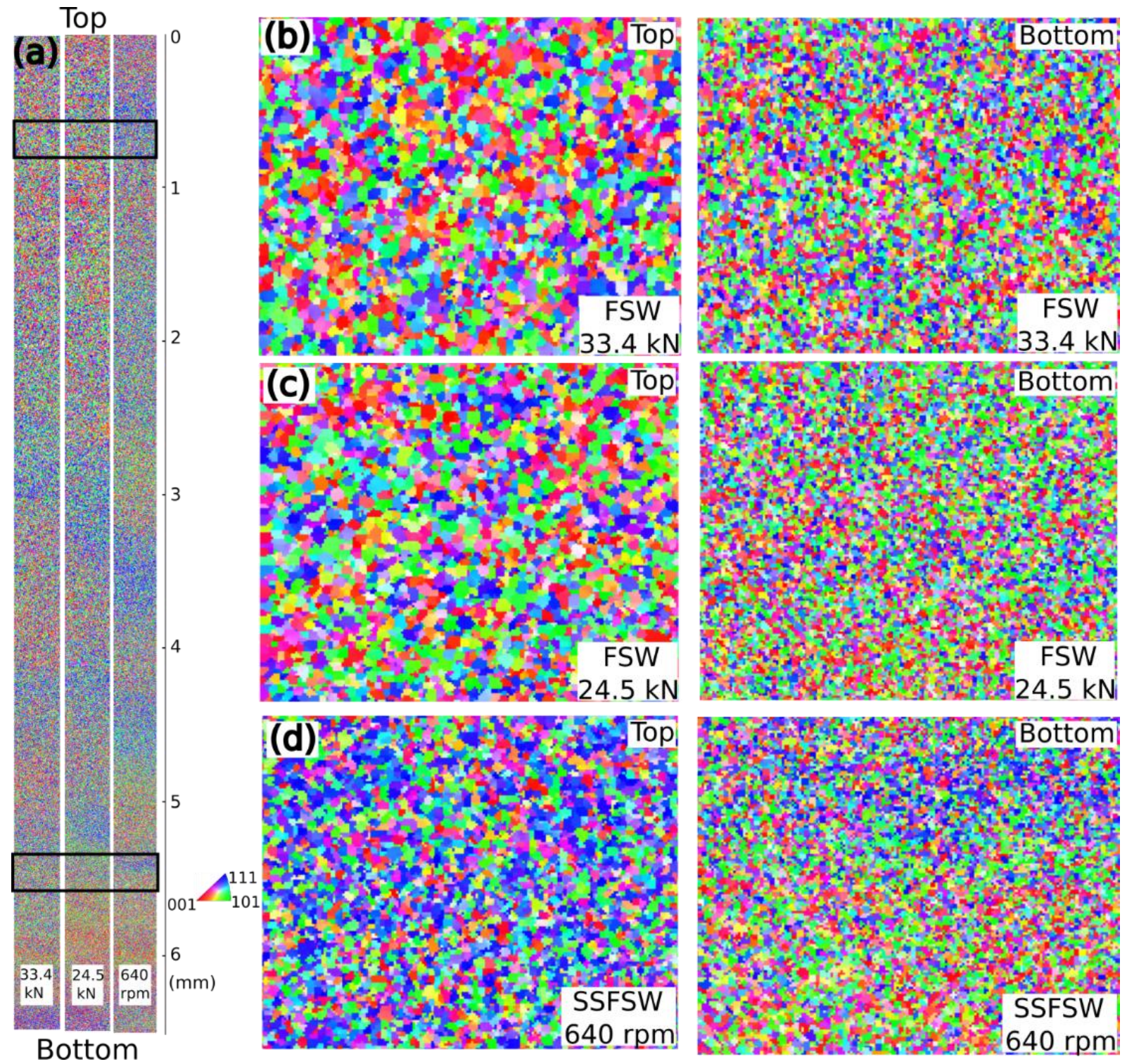

Fig. 6: EBSD IPF coloring maps (with respect to ND), (a) through the entire thickness of the weld nugget (from the areas indicated in Fig. 2), and enlarged examples from near the top and bottom of each weld from the positions indicated, for (b) FSW with the highest downforce $(32.4 \mathrm{kN})$, (c) FSW with the lowest downforce $(24.5 \mathrm{kN})$ and (d) SSFSW $(640 \mathrm{rpm})$ with the same input power as FSW $24.5 \mathrm{kN}$. 
(a)

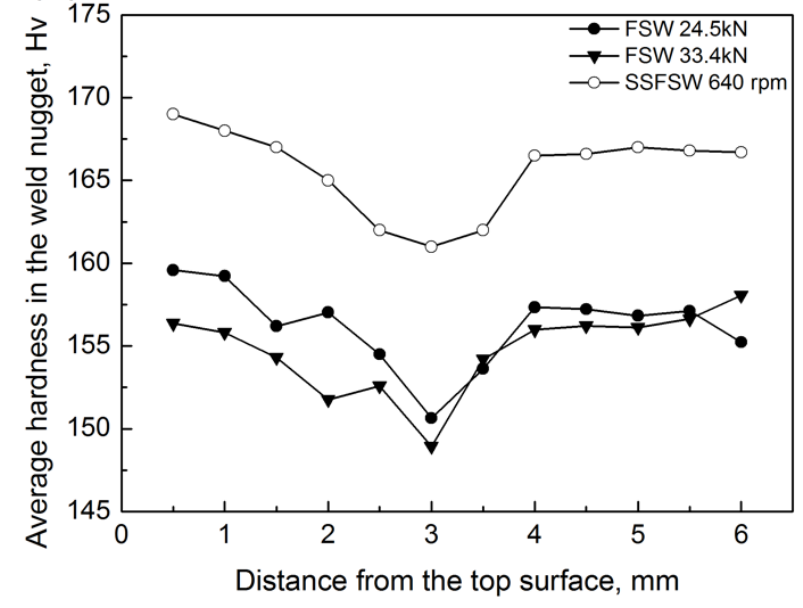

(b)

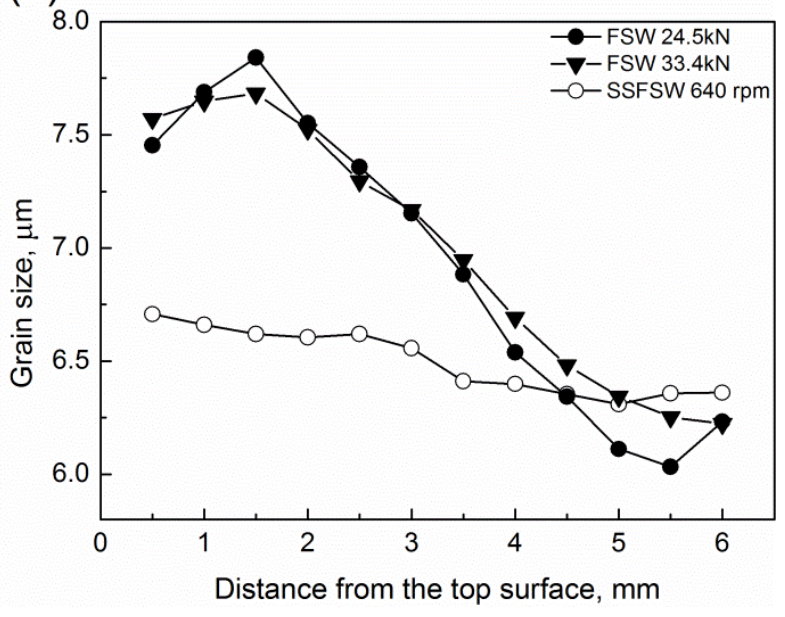

Fig. 7: Average (a) hardness and (b) grain sizes measured as a function of depth from a weld's top surface, down the nugget center, as indicated in Fig. 2, for the FSWs with a high $(33.4 \mathrm{kN})$ and low $(24.5 \mathrm{kN}$ ) downforce, compared to the SSFSW (all produced at $640 \mathrm{rpm}$ and $400 \mathrm{~mm} / \mathrm{min}$ ).

It has been proposed by Hassan et. al [19] that the recrystallized grain size in a weld nugget (where geometric dynamic recrystallization occurs) should be of the order of the steady state subgrain size, $d$, if there is no grain growth, following the relationship:

$$
\begin{aligned}
& d^{-1}=a+b \ln Z \\
& Z=\dot{\varepsilon} \exp (Q / R T)
\end{aligned}
$$

where $\mathrm{a}$ and $\mathrm{b}$ are constants, and $\mathrm{Z}$ is the Zener-Hollomon parameter, where $\dot{\varepsilon}$ is the strain rate, Q is the activation energy, $R$ is the gas constant and $T$ is the temperature $[33,34]$. From Eqn. (1-2) it is apparent that grain size is mainly determined by the temperature and to a lesser extent by strain rate. Reynolds [35] has also shown that the strain rate is mostly controlled by the tool rotation rate and travel speed, which were constant in the present work. Subsequent studies have shown that in FSW the final grain size is strongly affected by grain coarsening [19, 21], which is dominated by the peak temperature in the welding cycle. As identical rotation rates and travel speeds were used, here it seems reasonable to infer that the differences in grain size between the FSW and SSFSW welds were mainly determined by differences in the local temperature and, therefore, grain size measurements can be used to independently check the relative probe temperatures measured experimentally. Fig. 6 shows example EBSD maps and Fig. 7(b) summarizes the average grain size, as a function of distance from the top surface down the weld centers. The EBSD maps show some evidence of textural banding, but in all cases the weld nuggets can be observed to contain extremely fine recrystallized equiaxed grains, with a diameter in the range of 6 to $8 \mu \mathrm{m}$. Although it should be 
noted that this is a fine grain size, the Hall-Petch effect in aluminum alloys is relatively weak compared to precipitation hardening and this does not result in a large contribution to the yield strength increase of the nugget, which is dominated by the extent of solutionisation and subsequent natural ageing [19, 21]. For example in Fig. 7(a) it can be seen that the hardness decreases slighty with reducing grain size from the top to the bottom of the weld, owing to the reducing peak weld temperature with depth and its related effect on solutionisation. (The dip in hardness seen at the mid dpeth positon reflects the macrosegration previously noted in the plates welded).

It is clear from Fig. 7(b) that the SSFSW shows a finer and more uniform grain size, which implies a lower and more homogeneous temperature distribution through the weld nugget thickness. It can also be seen from Fig.7(b) that reducing the downforce in the FSW process had far less of an effect than using a stationary shoulder on the grain size profiles and weld temperature. This is consistent with the probe temperature measurements and hardness profiles in Fig. 1(b) and 7(a), and suggests the average weld temperature was significantly lower for the SSFSW process when the same rotation rate was used. Compared to SSFSWs, the grain size and hardness in the FSWs changed more dramatically from the top to bottom surface and were much higher in the top half of the weld than in the SSFSW. However, the grain sizes tend to converge for both processes at the weld root, where there is less influence of the shoulder, and became slightly finer in the FSWs relative to the SSFSWS. The grain size profiles thus indicate that the temperatures in the FSW weld nugget were significantly higher than in the SSFSWs near the top surface, but were lower at the weld base.

The microstructure in the weld nuggets were also examined by SEM to better explain the hardness response of the weld nugget region to the temperature measurements and allow comparison of the behavior of the secondary phases with respect to the hardness profiles shown in Fig. 3. Fig. 8 compares the nugget microstructures at $0.8 \mathrm{~mm}$ from the top surface in the weld nugget. Overall, it is evident that the SSFSWs contained less second phase particles than any of the FSWs, although in the FSW process, surprisingly, the level of second phase particles appears to reduce with a lower down force and peak weld temperature. At higher magnification, little matrix precipitation can be seen in any of the welds. However, copious grain boundary precipitation, having the appearance of almost a continuous film, can be observed in the FSW produced with the high downforce and to a lesser extent in the weld with the lower downforce; with significantly less grain boundary phases seen in the SSFSW. In the high downforce weld, this appears to be associated with weld defects that appear like hot tears. From the lower volume fraction of coarse second phase particles present in the SSFSW weld, it is evident that the nugget was close to being fully solutionised during welding, which is reflected in the higher nugget zone hardness seen in Fig. 3, compared to that of the FSWs. In comparison, in the FSWs it is apparent that more solute has been lost to grain boundary second 
phases, which would reduce the hardness recovery by natural ageing. Given the weld nugget temperatures were high enough for solutonisation in the FSWs (and higher than in the case of the SSFSW), this high volume fraction of grain boundary precipitation could have occurred by two possible mechanisms [19]; i) from grain boundary nucleation primarily of the $\eta$ equilibrium phase on cooling after welding, or ii) local grain boundary melting during the welding process, owing to the 7050 alloy's relatively low liquation temperature $\left(487^{\circ} \mathrm{C}\right)$ being exceeded. As the temperature measured at the weld mid thickness in the tool probe was over $480{ }^{\circ} \mathrm{C}$ (for the high down force weld; Fig. 1b), which is deeper than the sample position shown in Fig. 7, and tears were present in the microstructure (Fig. 8a), it seems more likely that the FSWs had overheated near the weld crown and the subsequent formation of grain boundary eutectic has removed solute from the matrix and this resulted in a reduced nugget hardness level, relative to that measured for the SSFSWs.
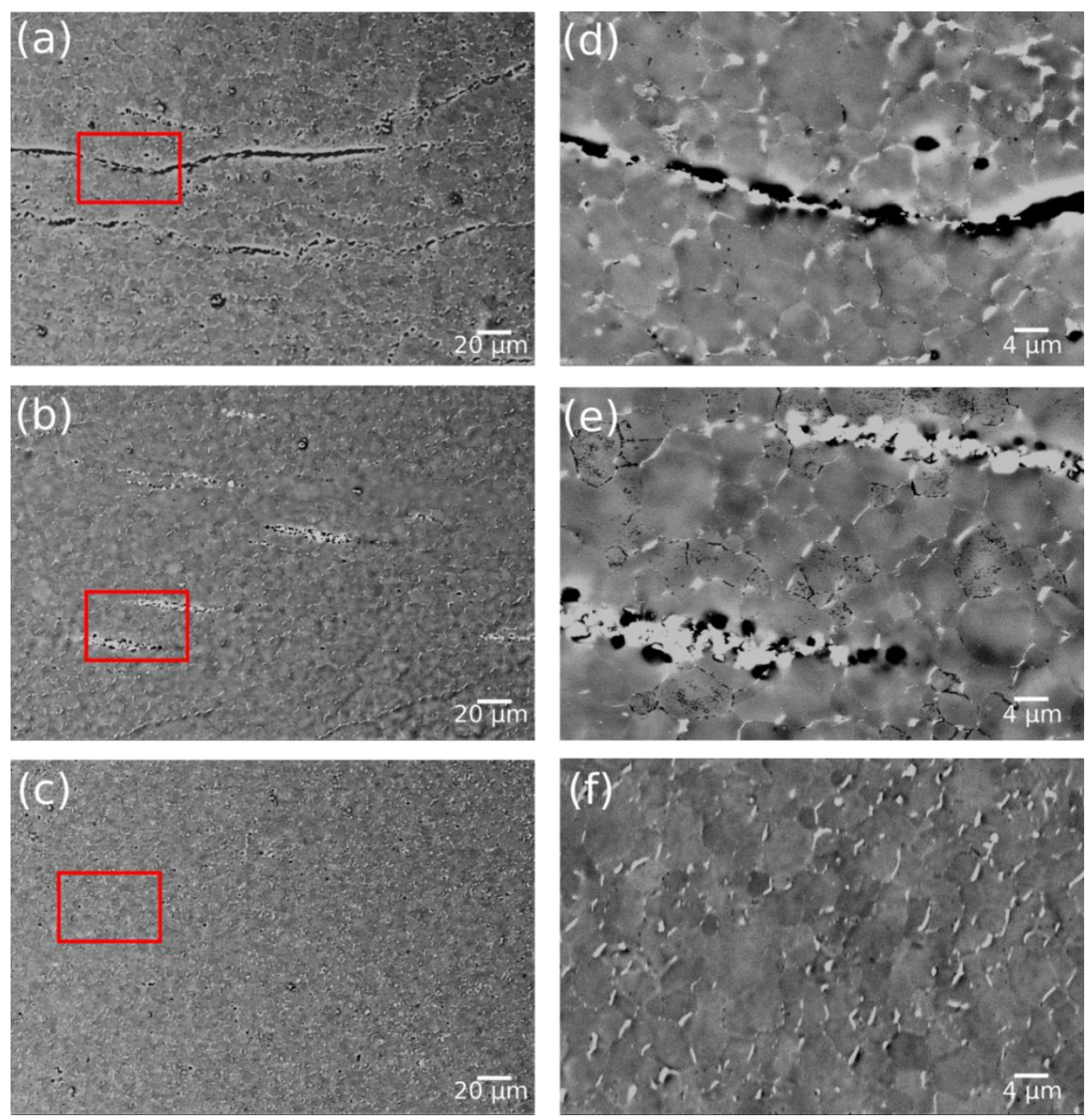

Fig. 8: Examples SEM micrographs taken from approximately $0.8 \mathrm{~mm}$ from below the top surface in the weld center for the FSWs; with (a) a high $(34.5 \mathrm{kN})$ and (b) a low down force $(24.5 \mathrm{kN})$ and compared to (c) a SSFSSW (all produced with the same $400 \mathrm{~mm} / \mathrm{min}$ travel speed and $640 \mathrm{rpm}$ rotation rate); magnified areas indicated in (a), (b) and (c) are shown in (d), (e), (f). 

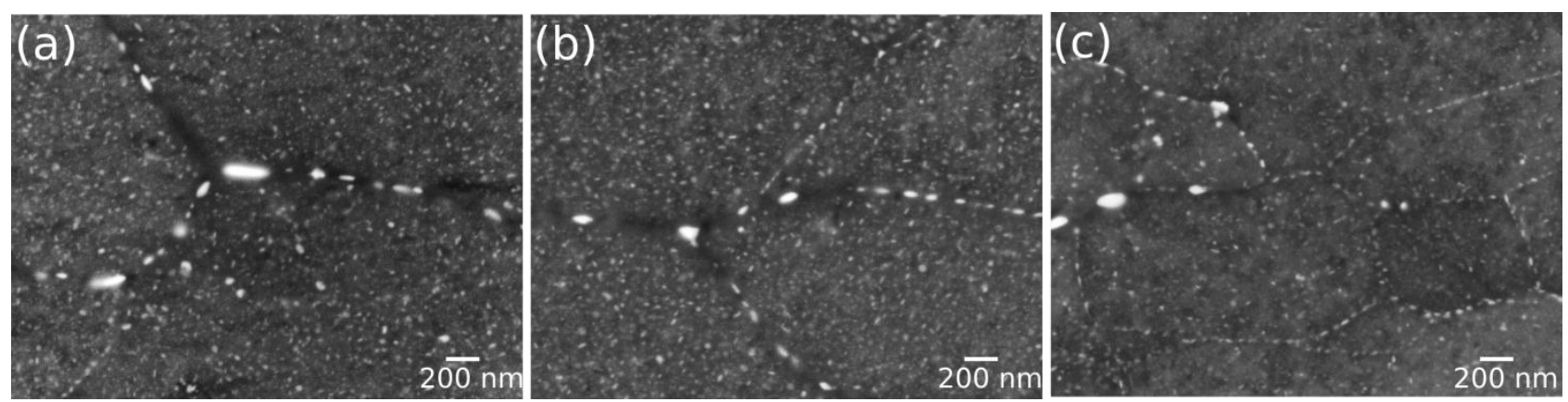

Fig. 9. SEM images from the HAZ minima positons at the mid plate thickness for; (a) a high (34.5 $\mathrm{kN}$ ) and (b) a low down force $(24.5 \mathrm{kN}$ ) FSW and (c) a SSFSSW (all produced with the same 400 $\mathrm{mm} / \mathrm{min}$ travel speed and $640 \mathrm{rpm}$ rotation rate).

Higher magnification SEM images are also shown in Fig. 9 from the HAZ minima positons. These images show that the lower loss of strength in the HAZ in the SSFSWs has resulted from a reduction in the level of particle coarsening, or overageing at the HAZ minima position. This again can be attributed to the lower heat input from the SSFSW tool, which also behaves analogously to a more uniform, narrower, through-thickness heat source, and this reduces the integrated effective time in the critical temperature range that the most rapid over ageing occurs (e.g. $\left.\sim 350{ }^{\circ} \mathrm{C}\right)[30]$.

Overall, these observations thus confirm (e.g. [12]) that welding with a stationary shoulder produces welds with a narrower, more parallel, heat affected zone and lower through-thickness microstructure and property gradients. It has previously been shown that, because of the narrower and lower hardness reduction in the HAZ, SSFSWs perform better than conventional FSWs in cross-weld tensile tests [12]. In this work digital image correlation analysis of the strain distribution in the test pieces revealed that this resulted, not just from the higher minimum hardness in the HAZ, but also from the narrower and more parallel HAZ, which imposed greater constraint on the localisation of plastic strain during deformation.

\section{Residual stresses}

2D maps of the longitudinal residual stress distributions determined by the contour method from all the welds are shown in Fig. 10. Longitudinal (welding direction) residual stress line profiles across the welds at their mid-thickness are plotted in Fig. 11, to show the magnitude of the residual stresses in greater detail. It can be seen that for both the FSW and SSFSW processes, there is a tensile residual stress field across the weld center, balanced by compressive stresses further out in the plate. It is also apparent that the width of the tensile stress region in the FSWs is more uniform through the thickness than seen in our previous study [14], which is mainly due to the larger pin tool design and the use of downforce control; i.e. in the current welds the additional heat input generated by the larger pin is balanced by less heat input from the shoulder, when operating in 
downforce control. When combined, this leads to a more uniform heat distribution through the plate thickness which results in a more uniform residual stress distribution than in our previous study [14].

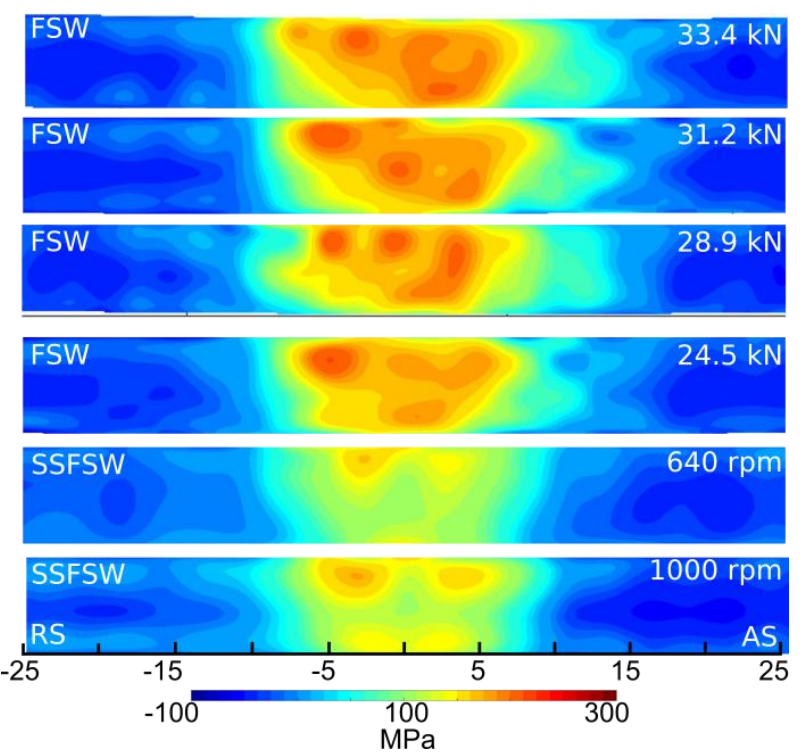

Fig. 10: Comparison of the longitudinal residual stress maps measured by the contour method for the FSWs and SSFSWs. The welding parameters are shown on each map.

(a)

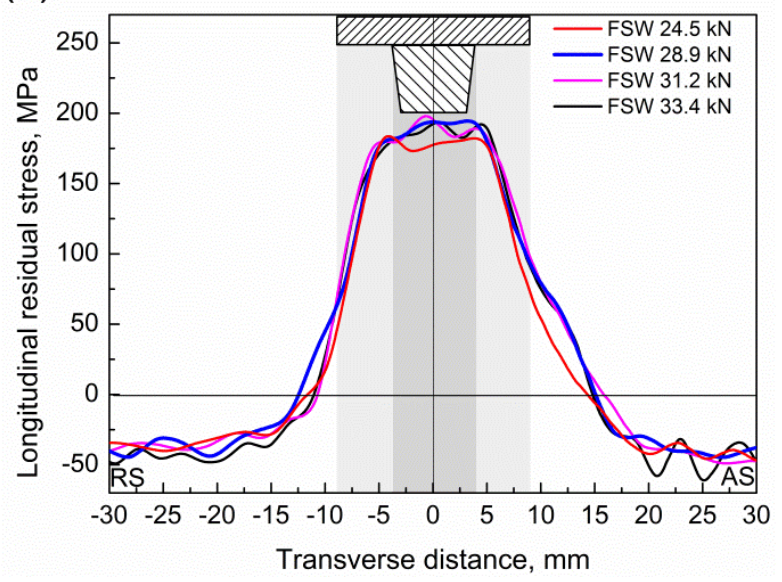

(b)

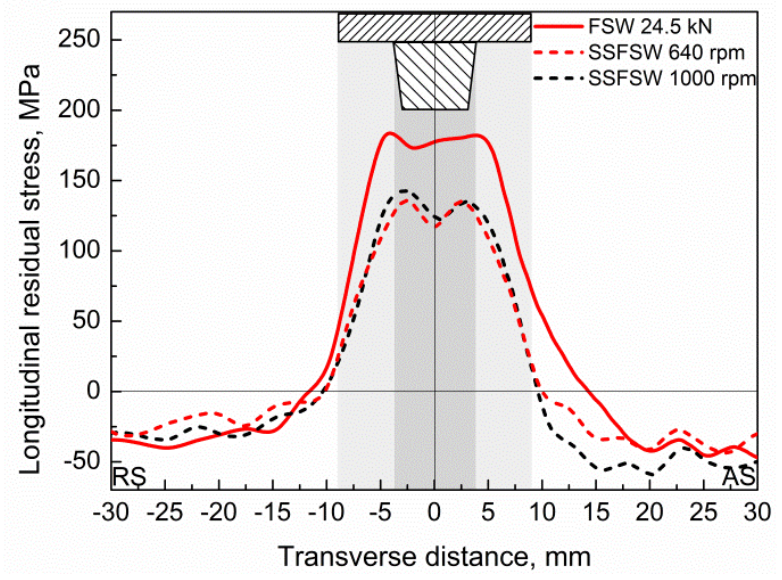

Fig. 11: Longitudinal residual stress distributions across welds' mid-planes for; (a) FSW samples with different downforces and (b) comparison between the lowest downforce FSW and SSFSWs with the same $(640 \mathrm{rpm})$ and a higher rotation rate $(1000 \mathrm{rpm})$.

For both processes, the residual stresses exhibit an ' $\mathrm{M}$ ' shape profile, which is consistent with previously reported results for FSW of high strength aluminum alloys [37-39]. It can be seen in Fig. 11(a) that, similar to its influence on the hardness profiles (Figs. $3 \& 4$ ), reducing the tool downforce has had limited effect on the residual stress distributions. Over the whole downforce range studied (which was reduced from 33.4 to $24.5 \mathrm{kN}$ ) the peak residual stresses and the widths of 
the tensile stress zones were nearly the same, within the achievable accuracy by the contour method [40], despite this leading to a significant reduction in the power dissipation and temperature recorded in the FSW tool shoulder, and a smaller reduction in temperature in the pin.

In comparison, it can be seen in Fig. 11(b) that for an identical travel speed, rotation rate (640 rpm) and nominally the same input power as for the lowest downforce FSW, the tensile residual stress field in the SSFSW was much narrower and had a lower magnitude. For example, there was approximately a $27 \%(50 \mathrm{MPa})$ reduction in the peak tensile residual stress and $21 \%(5.5 \mathrm{~mm})$ reduction in the width of the tensile stress zone, compared to the low downforce $(24.5 \mathrm{kN}) \mathrm{FSW}$. Interestingly, increasing the rotation rate to $1000 \mathrm{rpm}$, which led to a higher welding power and nugget temperature than for the FSW process (Fig. 1), still did not increase the peak residual stresses into the same range as seen for the conventional FSW welds.

As discussed previously by Richards [41], the residual stress distribution in FSW welds produced with high-strength Al-alloys is highly sensitive to the extreme softening behavior that occurs in such materials at temperatures approaching their melting point. However, the final residual stress state is also very dependent on the cooling behavior behind the welding tool. This is because tensile stresses only become 'fixed in' when the yield surface separates from the stress generated by the increasing tensile misfit, as the material cools and the material's yield stress rises rapidly with falling temperature $[41,42]$.

It is therefore worth considering what is the most dominant parameter affecting residual stresses in FSW. In Fig. 12, all our available data has been summarized, by plotting the peak residual stresses measured here with results from prior work [14] against the key process parameters of interest, i.e. travel speed, rotation rate, downforce and shoulder type. The current results are annotated in red. Overall, from Fig. 12 (a) and (b) it can be seen that, by comparison with the prior data, one of the most important parameter is the travel speed, whereas the downforce and rotation rate have a lower effect on the magnitude of residual stresses. However, with the current results there was also a much more marked reduction in the peak residual stresses when using the stationary shoulder tool. In this case, the tools were both operated at the same rotation rate, which the microstructure analysis above has confirmed led to a more significant reduction in the peak weld temperatures. In contrast, in the prior data this difference was less pronounced because a smaller pin diameter (6.2 $\mathrm{mm}$ ) was used, which meant the welds could not be compared with the same tool rotation rate and the SSFSWs were probably relatively hotter as they were produced with approximately double the rotation rate of the FSWs. In the previous work the FSW welds were also produced in positon 
control with a plunge depth of $0.2 \mathrm{~mm}$, to ensure maximum shoulder coupling; thus heating by the shoulder was maximized.

(a)

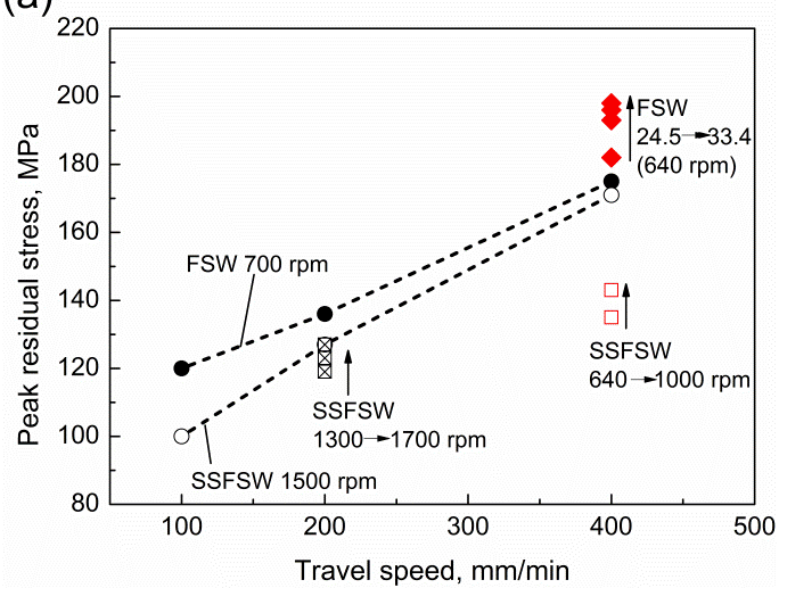

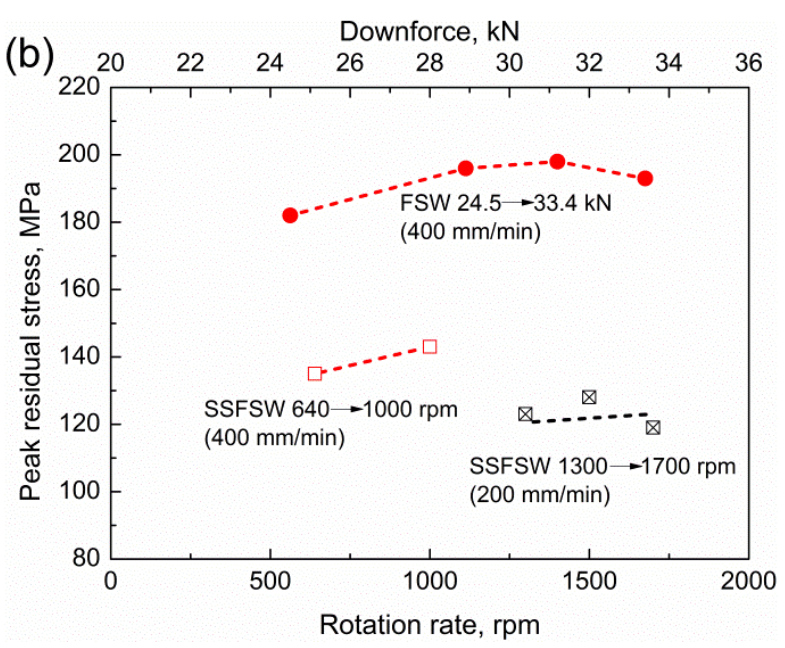

Fig. 12: Summary of peak longitudinal residual stress data amalgamated with prior work (reference [14]) plotted; (a) against travel speed and (b) downforce. The current results are annotated in red. Note; the prior data used a smaller probe dimeter $(6.2 \mathrm{~mm})$ and for FSW was obtained in positon control. In (b) the current data for FSW against downforce is for a fixed rotation rate $(640 \mathrm{rpm})$ and travel speed $(400 \mathrm{~mm} / \mathrm{min})$, whereas the SSFSW rotation rate data is for the same fixed travel speed and a down force.

In Fig. 12(a) it can be seen that in the previous results, where the rotation rate of the SSFSW tool was doubled relative to that of FSW, to compensate for a lower welding power when using a smaller diameter tool, there was a less marked reduction in peak residual stresses when using a stationary shoulder tool than in the present work, where both tools were operating at the same rotation rate. In comparison the present results, which were produced with the same rotation rates and a reduced downforce to obtain a similar energy input, thus confirm that the stationary shoulder leads to a more significant residual stresses reduction when welds are produced with identical welding parameters. For the present welds, although similar input powers were recorded for the FSW and SSFSW, the tool temperature measurements and microstructural evidence (e.g. nugget grain size) suggest the weld temperatures, at least in the top half of the welds, was significantly lower in the SSFSWs. At present, it has not been possible to establish why the average weld temperatures differed with a similar level of measured power dissipation; however this does not affect the key finding of a strong correlation between lower peak residual stresses and a lower, more uniform welding temperature with the SSFSW process. This discrepancy could possibly be explained by the different temperature distributions in the two welds, i.e. the FSW was hotter at the 
top and colder at the base, while the average power input was similar. Different base plate contact conditions could have also influenced the weld temperatures due to less distortion with the SSFSWs [12].

For a fixed travel speed, a higher heat input and larger heat source (e.g. in FSW) will lead to a larger area that expands when the workpiece temperature rises as the tool approaches. When combined with a higher weld temperature, this also leads to a larger region that is thermally softened enough to plastically relax, leading to a larger area that has experienced a compressive plastic misfit to generate a tensile misfit on subsequent cooling behind the tool [43]. The hardness maps in Fig. 3 show that the thermal field in the FSW process was larger than for the stationary shoulder weld. Therefore, the footprint over which compressive plastic deformation occurs when the welding tool approaches will also be wider. When combined with a higher weld temperature, at least in the top half of the weld, this would be expected to result in a wider tensile residual stress zone with larger peak residual stresses.

Despite the heat input decreasing with a lower downforce in the FSW welds, this does not appear to have had a dramatic effect on the residual stress distribution. This could be because the effect of the relatively small reduction in heat input $(20 \%)$, that it was possible to obtain by reducing the downforce, was not significant enough to be detected in the residual stress results. However, another factor specific to FSW that is not seen in a fusion process is that the rotating shoulder effectively fixes the minimum heat source size; because the maximum rate of heat generation is near the edge of the shoulder owing to the higher relative surface velocity at this position.

Previously it has been suggested that in FSW the level at which the residual stresses become 'locked-in' (i.e. the point at which relaxation ceases) is more dependent on the weld travel speed than the heat input or rotation rate [14]. Increasing the travel speed does not appreciably increase the welding power in FSW and this thus reduces the effective heat input, or line energy [44], but also strongly affects the width of the thermal field and the cooling rate after the heat source passes [14]. At higher travel speeds, the thermal field shrinks closer to the tool and this, combined with the higher associated cooling rates, will lock-in a larger residual tensile stress. This occurs because the material's yield strength will increase more quickly closer to the tool with falling temperature and therefore retain a greater proportion of the tensile misfit generated on cooling due to less plastic relaxation. This effect seems to be more important than the peak weld temperature, because at high temperatures the yield stress of the material is extremely low over a wider temperature range and there is thus less sensitivity to the absolute compressive plastic misfit. Within the viable process window, increasing the tool rotation rate, or reducing the downforce used in FSW to influence the shoulder-work piece coupling, therefore has less effect on the peak residual stresses when compared 
to increasing the weld travel speed or removing the shoulder heat input by using a stationary shoulder.

\section{Conclusions}

In the present study, the effect of changing the shoulder-workpiece coupling conditions on the relationships between the hardness, microstructure and residual stress distribution seen in friction stir welds has been investigated, for a typical high strength Al-alloy (AA7050). This was achieved by reducing the downforce on the tool in the conventional FSW process, and comparing the results to stationary shoulder welds produced under identical conditions. The results have been discussed relative to data from a previous study where a smaller diameter pin and double the rotation rate was used for the SSFSW process to be able to weld with similar heat inputs.

In general, these results confirm that a wider thermal field is found with FSW relative to in SSFSW, when identical welding parameters are used. In particular, the additional heat generated by the shoulder in FSW expands the welds at the top surface and leads to greater through thickness temperature variation. The narrower and more uniform through thickness temperature profile in SSFSW is beneficial from the point of view of obtaining a narrower weld zone with a more uniform through-thickness microstructure and avoiding overheating near the weld crown.

Reducing the tool downforce in FSW was not found to make as significant a difference to the hardness and residual stress distribution as using a stationary shoulder. When operated at the same rotation rate, the SSFSW process was found to lead to overall lower and more uniform throughthickness weld temperatures and a substantially a reduced HAZ width, as well as, importantly, a lower loss of strength at the HAZ minima positions, which would be expected to increase the joints' mechanical efficiency.

When applying SSFSW using the same welding parameters as in FSW, there was approximately a $20 \%$ reduction in width and a $25 \%$ decrease in the peak magnitude of the tensile residual stresses. This improvement was mainly caused by the more concentrated thermal field in SSFSW, and lower weld temperatures, which reduced the compressive plastic misfit generated during welding. Although the influence of the residual stresses on weld performance have not yet been determined, it is anticipated this reduction in peak residual stresses and narrowing of the region of tensile residual stress will have an important beneficial influence on key joint properties, such as the initiation and propagation of fatigue cracks. 


\section{Acknowledgements}

We are grateful for the financial support provided by the China Scholarship Council. We would also like to thank Mr. Ian Winstanley for performing the contour cuts and Mr. Daniel Wilhelm, Department of Mechanical Engineering, University of South Carolina, Columbia, SC, USA for his help in preparing the FSW weld joints. M.J. Roy acknowledges the financial support from the EPSRC (EP/L01680X/1) through the Materials for Demanding Environments Centre for Doctoral Training.

\section{References}

[1] R.S. Mishra, M.W. Mahoney, Friction stir welding and processing, ASM International, 2007.

[2] P. L. Threadgill, A. J. Leonard, H.R. Shercliff, P.J. Withers, International Materials Reviews, 54 (2009) 49-93.

[3] M.J. Peel, A. Steuwer, P.J. Withers, Metallurgical and Materials Transactions A, 37 (2006) 2195-2206.

[4] M.J. Peel, A. Steuwer, P.J. Withers, T. Dickerson, Q. Shi, H.R. Shercliff, Metallurgical and Materials Transactions A, 37 (2006) 2183-2193.

[5] P. Upadhyay, A.P. Reynolds, Materials Science and Engineering: A, 558 (2012) 394-402.

[6] P.A. Colegrove, H.R. Shercliff, R. Zettler, Science and Technology of Welding \& Joining, 12 (2007) 284-297.

[7] K. Kumar, S.V. Kailas, Materials \& Design, 29 (2008) 791-797.

[8] J. Altenkirch, A. Steuwer, P.J. Withers, Science and Technology of Welding \& Joining, 15 (2010) 522-527.

[9] K. Elangovan, V. Balasubramanian, M. Valliappan, The International Journal of Advanced Manufacturing Technology, 38 (2008) 285-295.

[10] T. Li, Q. Shi, H.-K. Li, Science and Technology of Welding \& Joining, 12 (2007) 664-670.

[11] M. Russel, in: 7th International Friction Stir Welding Symposium, 2008.

[12] H. Wu, Y-C. Chen, D. Strong, P.B. Prangnell, Journal of Materials Processing Technology, 221 (2015) 187-196.

[13] M.N. Avettand-Fènoël, R. Taillard, Materials \& Design, 89 (2016) 348-361. 
[14] T. Sun, M.J. Roy, D. Strong, P.J. Withers, P.B. Prangnell, Journal of Materials Processing Technology, 242 (2017) 92-100.

[15] M.J.Peel, A. Steuwer, M. Preuss, P. J. Withers, Acta materialia, 51 (2003) 4791-4801.

[16] W. Woo, Z. Feng, X.L. Wang, S.A. David, Science and Technology of Welding and Joining, $16(2011) 23-32$.

[17] P. A. Colegrove, H.R. Shercliff, Science and Technology of Welding and Joining, 8 (2003) 360-368.

[18] J. Yan, A.P. Reynolds, Science and Technology of Welding and Joining, 14 (2009) 282-287.

[19] K.A. Hassan, A.F. Norman, D.A. Price, P.B. Prangnell, Acta materialia, 51 (2003) 1923-1936.

[20] Y.S. Sato, M. Urata, H. Kokawa, Metallurgical and Materials Transactions A, 33 (2002) 625635.

[21] J.D. Robson, L. Campbell, Science and Technology of Welding and Joining, 15 (2010) 171176.

[22] M.B. Prime, A.T. DeWald, Practical Residual Stress Measurement Methods, (2013) 109-138.

[23] C. Liu, X. Yi, Materials \& Design, 46 (2013) 366-371.

[24] M.B. Prime, T. Gnäupel-Herold, J.A. Baumann, R.J. Lederich, D.M. Bowden, R.J. Sebring, Acta materialia, 54 (2006) 4013-4021.

[25] Y. Zhang, S. Pratihar, M.E. Fitzpatrick, L. Edwards, in: Materials science forum, Trans Tech Publ, 2005, pp. 294-299.

[26] Y.G. Kim, K. Nakata, T. Murakami, T. KOMAZAKI, M. USHIO, Transactions of JWRI, 32 (2003) 41-42.

[27] J.E. Hatch, A. Association, Aluminum: properties and physical metallurgy, ASM International, 1984.

[28] R.S. Mishra, M. Komarasamy, Friction Stir Welding of High Strength 7XXX Aluminum Alloys, Butterworth-Heinemann, 2016.

[29] L. Zhou, T. Wang, W. Zhou, Z. Li, Y. Huang, J. Feng, Journal of Materials Engineering and Performance, 25 (2016) 2542-2550.

[30] A. Sullivan, J.D. Robson, Materials Science and Engineering: A, 478 (2008) 351-360.

[31] A.P. Reynolds, W. Tang, Z. Khandkar, J.A. Khan, K. Lindner, Science and Technology of Welding and Joining, 10 (2005) 190-199. 
[32] M. Wade, A.P. Reynolds, Science and Technology of Welding and Joining, 15 (2010) 64-69.

[33] E. Cerri, E. Evangelista, A. Forcellese, H.J. McQueen, Materials Science and Engineering: A, 197 (1995) 181-198.

[34] A. Gholinia, F.J. Humphreys, P.B. Prangnell, Acta materialia, 50 (2002) 4461-4476.

[35] A.P. Reynolds, Science and Technology of Welding and Joining, 5 (2000) 120-124.

[36] J.A. Wert, Scripta materialia, 49 (2003) 607-612.

[37] J. Altenkirch, A. Steuwer, M.J. Peel, D.G. Richards, P.J. Withers, Materials Science and Engineering: A, 488 (2008) 16-24.

[38] P. Carlone, G.S. Palazzo, The Open Mechanical Engineering Journal, 7 (2013) 18-26.

[39] M.A. Sutton, A.P. Reynolds, D.-Q. Wang, C.R. Hubbard, Journal of Engineering Materials and Technology, 124 (2002) 215-221.

[40] F. Martina, M.J. Roy, B.A. Szost, S. Terzi, P.A. Colegrove, S.W. Williams, P.J. Withers, J. Meyer, M. Hofmann, Materials Science and Technology, 32 (2016) 1439-1448.

[41] D.G. Richards, P.B. Prangnell, P.J. Withers, S.W. Williams, T. Nagy, S. Morgan, Science and Technology of Welding \& Joining, 15 (2010) 156-165.

[42] D.G. Richards, P.B. Prangnell, S.W. Williams, P.J. Withers, Materials Science and Engineering: A, 489 (2008) 351-362.

[43] D.G. Richards, P.B. Prangnell, P.J. Withers, S.W. Williams, T. Nagy, S. Morgan, in: 7th international symposium friction stir welding, TWI, Japan, 2008.

[44] P.A. Colegrove, H.R. Shercliff, Journal of Materials Processing Technology, 169 (2005) 320327. 